\section{ГЕОИНФОРМАЦИОННОЕ КАРТОГРАФИРОВАНИЕ МЕДИКО-ЭКОЛОГИЧЕСКОЙ СИТУАЦИИ В КРУПНОМ ПРОМЫШЛЕННОМ ГОРОДЕ (на примере г. Балаково)}

\author{
А.Н. Павлова, Н.А. Чумаченко, Е.И. Ермолаева' \\ Саратовский государственный университет, \\ кафедра геоморфологии и геоэкологии \\ E-mail: gis@sgu.ru \\ ${ }^{1}$ Министерство здравоохранения и социальной поддержки \\ Саратовской области \\ E-mail: mzsp@saratov.gov.ru
}

Данная работа посвящена анализу медико-экологической обстановки в современном крупном промышленном городе (на примере г. Балаково Саратовской области).

Предметом такого исследования является, прежде всего, изучение зависимости между загрязненностью окружающей среды в пределах города и заболеваемостью населяющих его жителей. В работе представлена методика геоинформационного картографирования, а также некоторые промежуточные результаты анализа медико-экологической обстановки в г. Балаково. Рассмотрен ряд закономерностей в вопросах зависимости между экологической обстановкой и заболеваемостью. Сформулированы некоторые общие принципы обработки исходных данных для такого рода исследований.

\section{Geoinformational Mapping of Medico-ecological Situation in Large industrial City (by the Example of Balakovo City)}

\section{A.N. Pavlova, A.N. Chumachenko, E.I. Ermolaeva}

Present paper is devoted to a problem of the analysis of medicoecological situation in large industrial city (by the example of Balakovo city of Saratov region). An object of such investigation is, first of all, the studying of correlation between pollution of the environment in the city and morbidity of citizens. In the current paper the GIS-method and some intermediate results of the analysis of medico-ecological situation in Balakovo are presented. Some features of input data processing are considered.

В настоящее время крупные промышленные города являются центрами острейших экологических проблем. Одно из негативных последствий прогрессирующей урбанизации - загрязнение городской среды и связанное с ним ухудшение здоровья населения. Утверждать, что состояние здоровья населения напрямую зависит от экологического состояния территории, неправомерно. Очевидно, что велика роль медико-генетических факторов, образа жизни и качества питания, уровня развития здравоохранения и др. В то же время отрицать существенное влияние различных неблагоприятных экологических параметров городской среды на здоровье человека нельзя. Показатели заболеваемости населения в большой степени можно считать индикаторами экологической ситуации в городе.

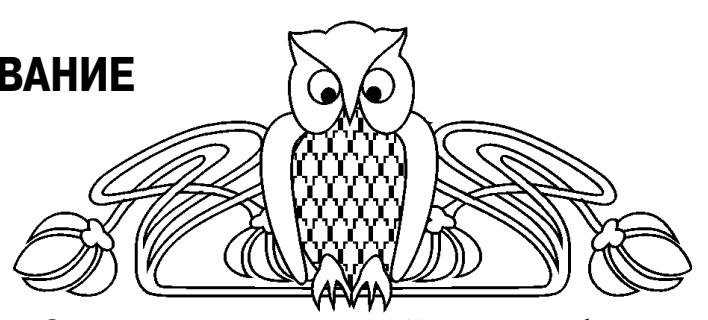

Оценка вклада каждой группы факторов в общую структуру заболеваемости населения является предметом медико-экологических исследований. Результаты таких исследований позволяют разработать научно обоснованный комплекс мер по первичной профилактике заболеваний, в этиологии которых присутствует экологический компонент. На физическое и психическое здоровье горожан оказывают непосредственное влияние высокие уровни антропогенной нагрузки, загрязнения, геохимические аномалии, низкое качество питьевой воды, шумовые и электромагнитные воздействия. Эта ситуация усугубляется скученностью населения, транспортными проблемами, визуальным однообразием застройки, отсутствием зеленых насаждений и др.

Таким образом, состояние здоровья населения жителей города зависит от множества факторов: социальных, экологических, санитарногигиенических, природно-ландшафтных, планировочно-функциональных и т.п. Все они взаимодействуют и пространственно варьируются. Отсюда возникают непростые задачи инвентаризации и учета всех факторов, влияющих на здоровье горожан. Еще более сложная и исключительно необходимая задача - определение корреляционных отношений между различными факторами и заболеваемостью населения города [1].

Исследование действия вредных факторов окружающей среды на состояние здоровья продолжает оставаться одной из наиболее актуальных научных проблем современности. Решение этой проблемы вряд ли может быть абсолютным. В то же время анализ территориальных аспектов медико-экологических проблем и поиск наиболее значимых факторов, обусловливающих ухудшение здоровья населения, позволяют выстраивать систему мероприятий по улучшению экологической ситуации и принятию управленческих решений по медицинскому обслуживанию населения конкретных участков городской среды уже сейчас.

К наиболее мощным и современным средствам подобного исследования и анализа относятся методы геоинформационного картографирования медико-экологической ситуации, а также математико-картографическое моделирование влияния экологических факторов на уровень заболеваемости населения с применением ГИС-технологий.

В данной работе представлена методика, а также некоторые промежуточные результаты анализа медико-экологической обстановки в Балаково. 
Балаково - второй по численности населения и промышленному потенциалу город Саратовской области. Рядом с городом находятся Саратовская ГЭС, Балаковская АЭС. Построены и производят продукцию химические и нефтехимические предприятия, предприятия машиностроения. Естественно, столь крупный промышленный узел, где на ограниченной площади сосредоточены десятки предприятий, создал ярко выраженную техногенную геохимическую аномалию, обусловленную крупнотоннажными выбросами и сбросами в воздушную и водную среды, и способную, в свою очередь, в той или иной мере повлиять на уровень заболеваемости жителей города.

Медико-экологическое исследование территории Балаково, по нашему мнению, должно включать следующие основные этапы:

1. Выбор операционной территориальной единицы (ОТЕ) анализа разнообразной информации.

2. Создание базы данных экологических параметров городской среды.

3. Расчет показателей загрязнения почвенного и снежного покрова по ОТЕ.

4. Создание базы данных медицинских показателей состояния здоровья населения Балаково.

5. Геокодирование (географическая привязка) медицинских показателей к электронной карте города.

6. Расчет показателей заболеваемости населения различными видами болезней по ОТЕ.

7. Геоинформационное картографирование медико-экологической ситуации и математикокартографическое моделирование влияния экологических факторов на уровень заболеваемости населения: создание карт, отражающих общую картину заболеваемости слоев населения, вычисление корреляционных зависимостей между отдельными заболеваниями и различными природными и техногенными факторами.

Выбор картографируемых территориальных ячеек - операционных территориальных единиц (OTE), которые бы отражали совокупность географических, экологических, социально-экономических предпосылок заболеваемости населения, является одной из проблем медико-экологического картографирования. В качестве элементарных картографируемых единиц могут быть приняты любые территориальные ячейки: административные - кварталы, педиатрические участки, геоэкологические - зоны воздействия промышленных предприятий, крупных автомагистралей и т.п. Именно для данных территориальных выделов в дальнейшем производится определение относительных стандартизированных экологических и медицинских показателей.

На наш взгляд, в качестве базовой ОТЕ медико-экологических исследований можно использовать границы так называемых морфотипов жилой застройки. Это территориальные выделы, относительно однородные по характеру и возрасту жилой застройки, расположенные в относительно схожих природно-ландшафтных и экологических условиях. Морфотипы жилой застройки как элементарные картографируемые единицы могут использоваться для природных, социальных, экономических исследований городской среды. В границах морфотипов анализируются и основополагающие медицинские показатели [1].

На территории Балаково с учетом типа застройки и функционального использования была выделена 201 ОТЕ: 7 - в центральном районе города, 73 - в заканальном и 121 - в островном районе, где преобладает частный сектор.

Несмотря на то что Балаково имеет сложную промышленно-селитебную застройку, в городе действует всего 3 стационарных поста, фиксирующих состояние воздушного бассейна. Иными словами, получение достоверной информации о пространственном распределении загрязняющих веществ в пределах городской территории является довольно сложной задачей. Учитывая этот факт, при анализе экологической обстановки в городе целесообразно рассматривать состояние почвенного и снежного покровов - природных сред, депонирующих загрязнения и легко доступных для изучения по любой заранее заданной сети точек отбора проб.

Для создания базы данных геохимических показателей использовались данные снегомерной съемки марта 1998 г. и литохимической съемки августа 1998 года. Как показывает опыт, геохимические аномалии на территории города достаточно устойчивы в течение нескольких лет. В то же время нужно отметить, что почва и снежный покров отражают различные временные характеристики загрязнения атмосферного воздуха. Так, содержание загрязняющих веществ в поверхностном слое городских почв является результатом многолетнего воздействия загрязненного атмосферного воздуха, в снежном покрове, очевидно, отражается существующее загрязнение атмосферного воздуха. В процессе съемки в городской черте и ближайшем пригороде было отобрано 149 снеговых и 305 почвенных проб. Фоновые пробы были взяты близ с. Маянга и Подлесное в 15 и 40 км к юго-западу от балаковского промышленного узла. В результате химического анализа получены данные по содержанию растворимой фракции металлов (подвижной формы) в фильтрате снеговой воды (жидкая фракция), содержанию тяжелых металлов в оставшейся на фильтре пыли (твердая фракция), а также по содержанию химических элементов в верхнем слое почвы. Места отбора почвенных и снеговых проб были нанесены на карты. Путем создания цифровой модели для каждого химического элемента пробы, методом интерполяции рассчитывались аналогичные показатели загрязнения для каждой ОТЕ. Для каждого территориального выдела также определялось превышение показателей загрязнения над фоновыми значениями. 
На картах загрязнения снежного покрова пылевыми выпадениями металлов (твердая фракция) показаны геохимические аномалии по отношению к фону по свинцу, цинку, мышьяку, никелю. Создан пакет карт, отражающих загрязнение снежного покрова.

Исходя из анализа почвенных данных, выявлены наиболее значительные геохимические аномалии относительно фона по содержанию свинца, серебра, цинка, олова, в меньшей степени - меди и фосфора. Загрязнение почв отражено на соответствующих моноэлементных картах, а также на карте суммарного загрязнения почвенного покрова тяжелыми металлами (рис. 1).

Анализ геохимических карт показал, что почвенный и снежный покровы Балаково оказались загрязненными многими тяжелыми металлами, что свидетельствует о высоком уровне техногенного давления на природную среду города предприятий стройиндустрии, теплоэнергетики, транспорта, химии, машиностроения.

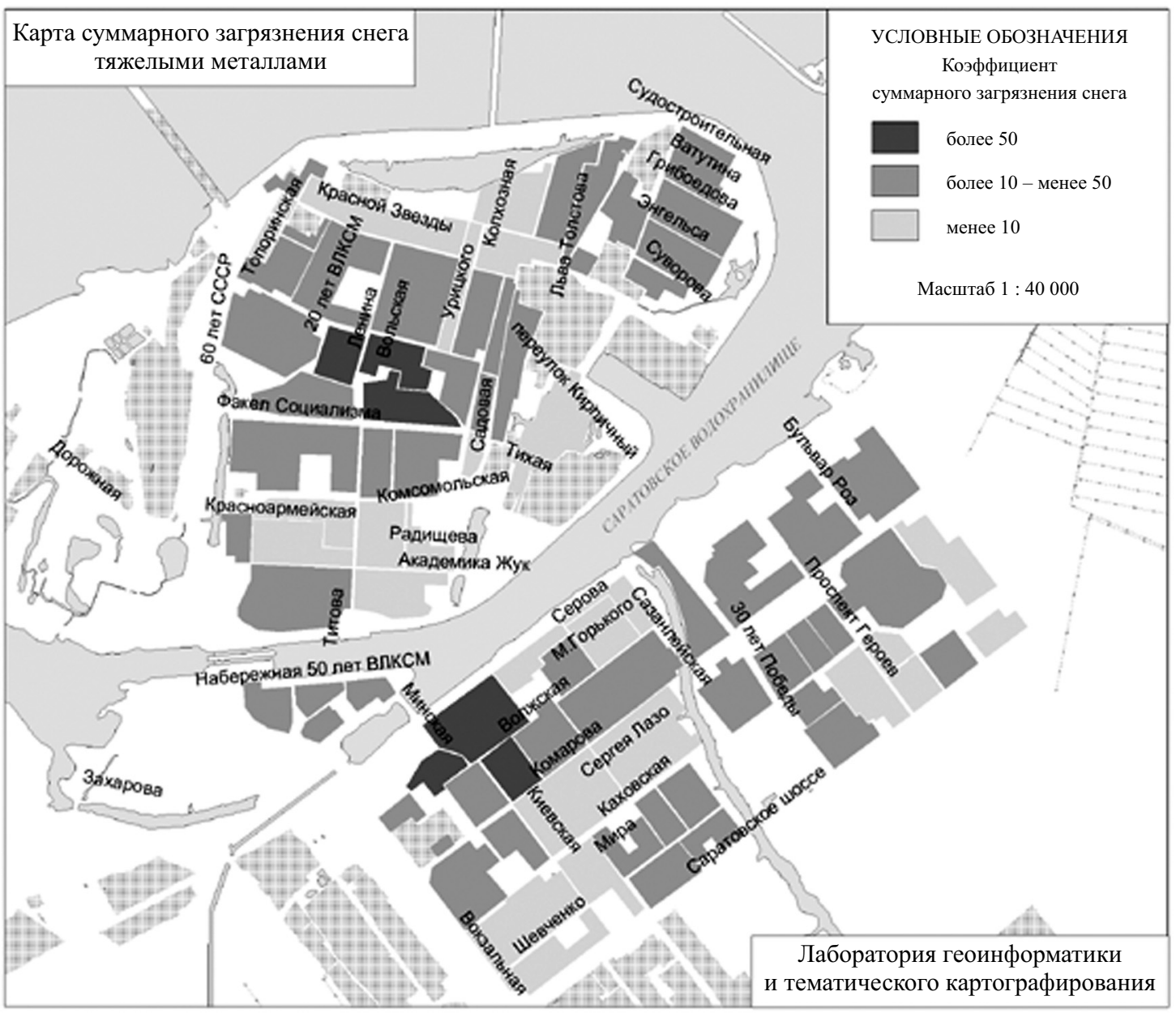

Рис. 1. Карта суммарного загрязнения снега тяжелыми металлами

Блок данных о состоянии здоровья при анализе медико-экологической ситуации в городе может включать самые разные показатели. В работах, посвященных изучению воздействия экологической обстановки на уровень заболеваемости, считается целесообразным учитывать заболеваемость детей.

Детский контингент - своеобразная индикаторная группа, отражающая реакцию населения на вредные воздействия факторов среды. Целесообразность учета именно детской заболеваемости определяется рядом факторов, среди них - меньшая подверженность детского населения внутригородской миграции, отсутствие влияния на здоровье профессиональных факторов, повышенная чувствительность к качеству среды обитания, связанная с анатомофизиологическими особенностями детского организма и др. Таким образом, анализ именно детского здоровья позволяет делать более объективные выводы об экологической обусловленности заболеваний [2].

Данное исследование здоровья населения города Балаково базируется на результатах проекта «Диспансеризация детей - 2002».

Исходя из анализа этих данных, можно сказать, что Балаково отличается неблагополучной медицинской ситуацией. Из 50 тыс. человек, охваченных диспансеризацией, только 10 тыс. можно считать здоровыми. $78 \%$ детского населения 
имеют какое-либо заболевание. На первом месте стоят заболевания опорно-двигательного аппарата, на втором - заболевания нервной системы и органов чувств (в частности, ослабленное зре- ние), на третьем - болезни эндокринной системы (рис. 2). Примерно 5 тыс. детей страдают стоматологическими заболеваниями и заболеваниями пищеварительного тракта.

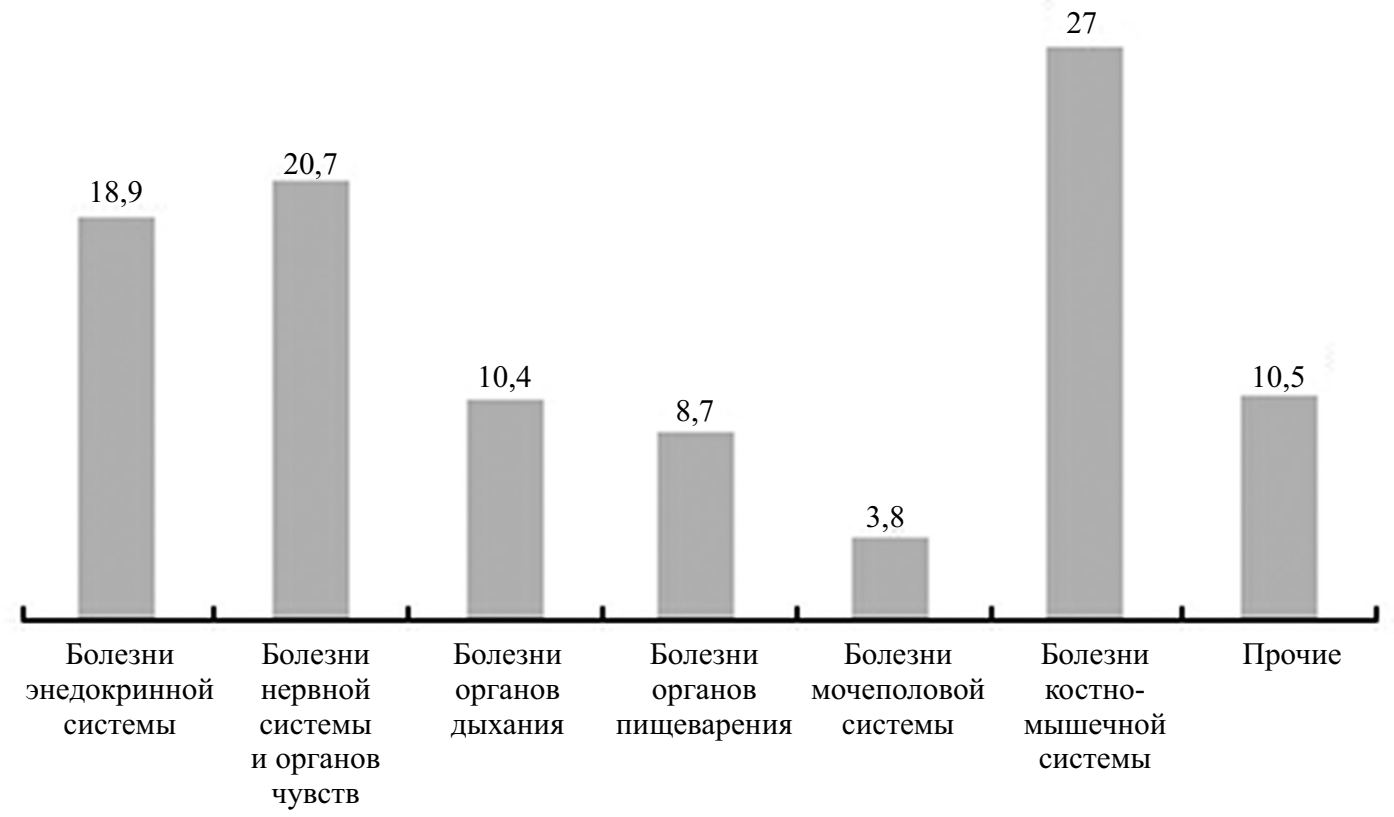

Рис. 2. Процентное соотношение детской заболеваемости (по данным проекта «Диспансеризация - 2002»)

Следующий этап - «привязка» данных диспансеризации к электронной карте Балаково. Для этого была использована геоинформационная система Балаково. По итогам геокодирования каждый ребенок был территориально локализован на карте города. Общее количество детей, проживающих в пределах городской черты, составляет 41980 человек. Далее данные диспансеризации, содержащие более 100 показателей, пересчитывались на выделенные территориальные единицы для последующего анализа взаимосвязи конкретных заболеваний с определенными факторами загрязнения окружающей среды. Заболеваемость детского населения оценивалась числом случаев заболеваний на 1000 детей по основным классам болезней в соответствии с международной классификацией болезней (МКБ-10):

- Инфекционные и паразитарные болезни.

- Новообразования.

- Болезни крови, кроветворных органов и отдельные нарушения, вовлекающие иммунный механизм.

- Болезни эндокринной системы, расстройства питания и нарушения обмена веществ.

- Болезни нервной системы и органов чувств.

- Болезни системы кровообращения.

- Болезни органов дыхания.

- Болезни органов пищеварения.

- Болезни кожи и подкожной клетчатки.

- Болезни костно-мышечной системы и соединительной ткани.

- Болезни мочеполовой системы.
- Травмы, отравления и некоторые другие последствия воздействия внешних причин.

В результате анализа этих данных был создан пакет медико-географических карт, отражающих заболеваемость вышеперечисленными классами болезней, а также отдельными видами заболеваний, в этиологии которых присутствует экологический компонент по ОТЕ. Так, в качестве примера можно привести карту, отражающую распространение заболевания щитовидной железы (рис. 3).

В блоке математико-картографического моделирования важное место занимает анализ корреляционной зависимости, который, в свою очередь, предполагает выполнение ряда подготовительных операций над массивами данных. Исходные данные, отражающие экологическую ситуацию и уровень детской заболеваемости в каждой ОТЕ, можно представить в виде матрицы из 201 строки, которые соответствуют ОТЕ, и 53 столбцов данных. Экологическую ситуацию описывает комплекс из 41 характеристики (результаты анализа проб почв - 22 характеристики, результаты анализа проб снега (твердая фракция) - 6 характеристик, результаты анализа проб снега (жидкая фракция) - 13 характеристик), уровень детской заболеваемости - 12 характеристик.

Характеристиками заболеваемости, как уже указывалось выше, является количество детей (из расчета на 10 тыс. детского населения ОТЕ), перенесших инфекционные и паразитарные болезни; имеющих новообразования; страдающих болезнями крови, кроветворных органов и отде- 


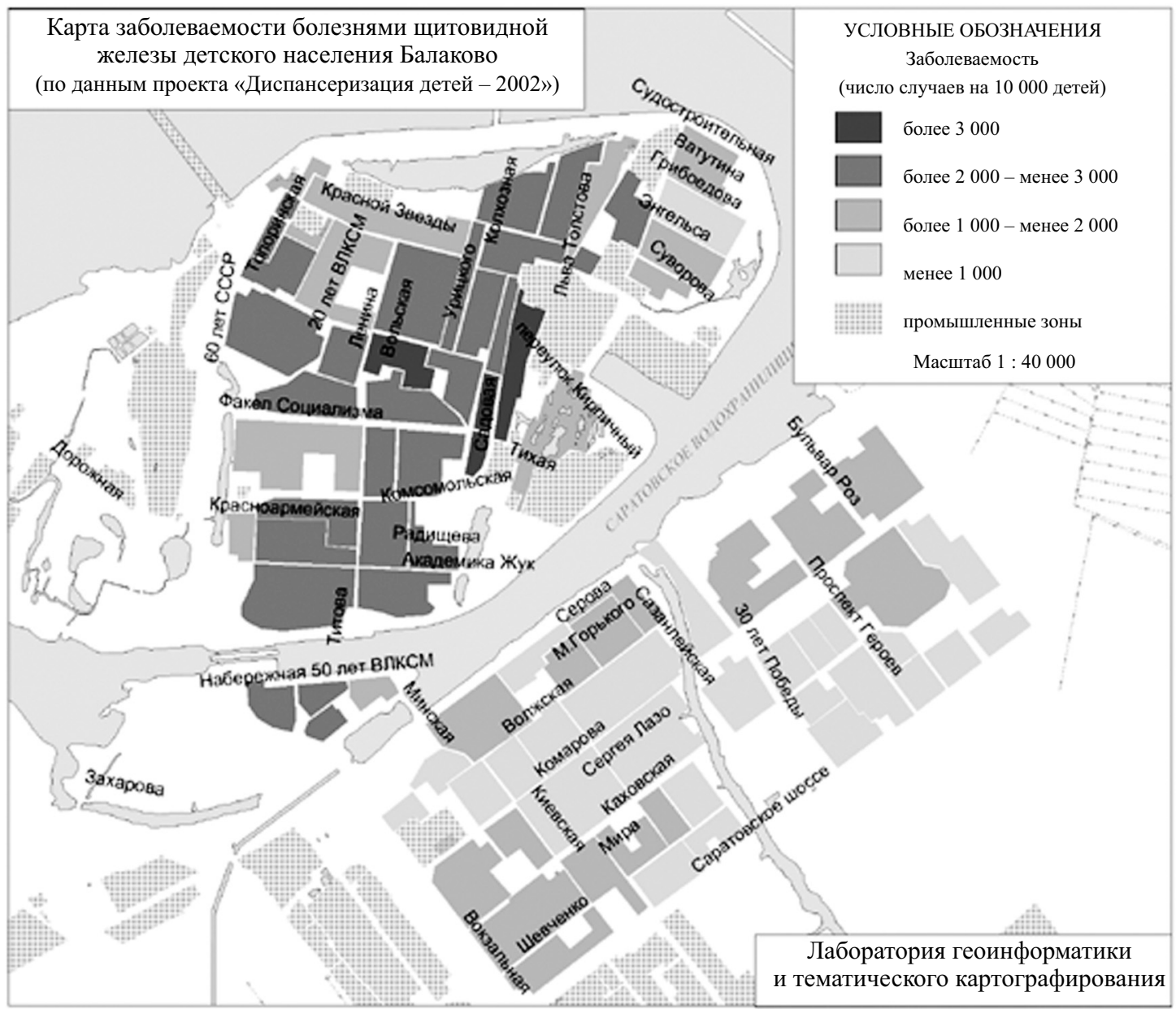

Рис. 3. Карта заболеваемости болезнями щитовидной железы детского населения Балаково

льными нарушениями, вовлекающими иммунный механизм, болезнями эндокринной системы, расстройствами питания и нарушением обмена веществ, болезнями нервной системы и органов чувств, болезнями системы кровообращения, болезнями органов дыхания, болезнями кожи и подкожной клетчатки, болезнями костно-мышечной системы и соединительной ткани, болезнями мочеполовой системы, получивших травмы, перенесших отравление и другие заболевания, связанные с воздействием внешних причин.

Очевидно, что среди выбранных для исследования 53 параметров многие являются несоизмеримыми друг с другом в силу того, что имеют разные размерности, а диапазоны их значений могут различаться не на один порядок. Для устранения этих неудобств и возможности в дальнейшем построить графики распределения значений каждой характеристики в одном масштабе произведена их нормировка по максимальным значениям таким образом, чтобы исследуемые характеристики располагались в диапазоне от 0 до 1 (при этом минимальное значение каждой из характеристик соответствует нулю, а максимальное - единице).
По результатам визуального анализа графиков распределения исследуемых характеристик были выявлены аномальные максимальные значения, которые впоследствии были удалены из рассмотрения.

Расчет корреляции предполагает вычисление коэффициентов корреляций двумя методами. Метод линейной корреляции (корреляции Пирсона) применяется для определения меры соответствия двух признаков, выраженных количественно, иными словами, для численных величин. Это параметрический метод, который (как и прочие параметрические) требует соответствия распределения данного исследуемого признака закону нормального распределения. В отличие от метода линейной корреляции, метод ранговой корреляции (корреляция Спирмена) применим к любым количественно измеренным или ранжированным данным. С помощью этого метода можно измерять согласованность изменения разных признаков у одного испытуемого или выявлять совпадения индивидуальных ранговых показателей у двух испытуемых.

Анализ результатов расчетов парных коэффициентов корреляции позволяет сделать вывод, 
что между собой характеристики различных групп коррелируют слабо. При этом особенно примечательным для нас является тот факт, что значения коэффициентов корреляции между показателями заболеваемости и степенью загрязнения не превосходят 0,5. Более того, это же относится и к которых измерялось в различных фракциях (свинец, цинк, никель, медь, мышьяк).

Однако некоторые параметры из числа характеризующих концентрацию химических элементов в окружающей среде довольно сильно коррелируют с другими аналогичными параметрами. Следовательно, можно сделать вывод об избыточности состава изначально выбранных знакового пространства.

Одной из целей данного исследования являного анализа. Проверка должна осуществляться в условиях полной уверенности в адекватности прочих составляющих. Ввиду отсутствия у нас такой уверенности мы можем априори принять саму методику пригодной для анализа соответствующих задач и, исходя из этого положения, искать упущения в формировании блока исходкак детальный анализ уже первых этапов исследования выявил основные проблемы и позволил сделать определенные выводы, что открывает в последующем два пути возможного развития исследования.

1. Как показали исследования, набор анализируемых параметров является избыточным, что затрудняет расчеты, создает массу лишних, трудно интерпретируемых нюансов («шумов»). Кроме того, не все из исследуемых заболеваний в той или иной степени могут зависеть от экологичесодним и тем же химическим элементам, наличие характеристик и необходимости снижения прилась проверка методики на пригодность подобных данных. Такой подход оправдал себя, так

кой ситуации, так же, впрочем, как и не все виды загрязнений способны непосредственно повлиять на здоровье человека. Таким образом, следует обратить особое внимание на существенные факторы. Проведенный корреляционный анализ уже позволяет наметить ряд из них.

2. Полученные в ходе предварительной разбивки территории города ОТЕ различаются между собой по площади, численности населения и др. Так, в пределах частной застройки есть ОТЕ, где количество детей не превышает 3-5 человек. Изза этого большое количество ячеек имеет нулевые показатели заболеваемости. Необходимо учесть при районировании территории плотность детского населения.

Авторы данной статьи изначально отдавали себе отчет в том, что коэффициенты корреляции не смогут в достаточной мере отразить причинно-следственные связи между заболеваемостью детей и параметрами экологического состояния территории. Слишком опосредованной является такая связь и слишком много факторов необходимо учитывать. В то же время корреляционный анализ - это один из первых и один из необходимых шагов для выяснения подобной зависимости и для дальнейшего районирования территории по результатам медико-экологического анализа.

\section{Библиографический список}

1. Жуков В. Т., Новаковский Б. А., Чумаченко А.Н. Компьютерное геоэкологическое картографирование. М., 1999. $128 \mathrm{c}$

2. Куролап Н.С., Барвитенко Н.Т. Медико-экологические аспекты оценки комфортности городской среды // Геоэкологические проблемы устойчивого развития городской среды. Воронеж, 1996. С.154-156.

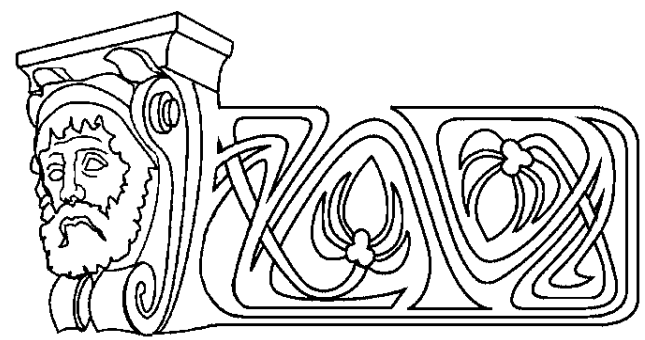

Agrometeorological Forecasts of the Quality of Winter and Spring Wheat in Saratov Region

\section{S.I. Pryakhina, Yu.A. Skliarov, M.Yu. Vasilieva}

кафедра метеорологии и климатологии

E-mail:kafmeteo@sgu.ru

В работе представлен прогноз качества зерна яровой пшеницы, полученный на основе корреляционной связи белковости зерна со средней месячной температурой воздуха июня. Полученное авторами уравнение позволяет оценить качество зерна с месячной заблаговременностью, что имеет важное значение в организации заготовки зерновых культур.
The forecast of the spring wheat quality is represented in this work. The forecast is composed on the grounds of correlation of the amount of protein in cereal with mean monthly air temperature in June. The equation derived by the authors lets to estimate the cereal's quality in monthly advance. The forecast of the quality of the new harvest cereal composed in advance has an important meaning in organization of cereal provision. 